At Turots: Jurnal Pendidikan Islam
Vol. 2, No. 2, Desember 2020, pp. $99-117$
Print ISSN : 2656-7555 || Online ISSN : 2747-089X
http://journal.stitmadani.ac.id/index.php/JPI/index

\title{
Pengaruh budaya organisasi terhadap peningkatan motivasi kerja di Islamic Center Bin Baz (ICBB) Yogyakarta
}

\author{
Roidah Lina a,1, ${ }^{*}$, Amiroh Hasanah a,2, Uswatun Hasanah a,3 \\ a Sekolah Tinggi Ilmu Tarbiyah Madani Yogyakarta, Yogyakarta, Indonesia; \\ *1 roidahlina@gmail.com; 2 hasanahamiro@gmail.com; ${ }^{3}$ uswatunha@gmail.com
}

\section{KATAKUNCI}

Pengaruh.

Budaya Organisasi.

Motivasi Kerja.

KEYWORDS

Influence.

Organizational Culture.

Work Motivation.
ABSTRAK

Nampak jelas bahwa rasa kepuasan mampu melahirkan perilaku kerja yang positif, penuh semangat, berorientasi pada hasil yang baik, totalitas dalam bekerja, cekatan dan lain sebagainya. Namun sayangnya paparan tersebut belum terlihat secara merata di Pondok Pesantren Islamic Center Bin Baz (ICBB). Untuk itu, diperlukan penelitian tentang pengaruh budaya organisasi terhadap peningkatan motivasi kerja di Islamic Center Bin Baz (ICBB) Yogyakarta. Penelitian ini menggunakan analisis data kuantitatif. Hasil penelitian menunjukkan bahwa terdapat pengaruh budaya organisasi terhadap motivasi. Terdapat pengaruh Budaya Organisasi terhadap Motivasi. Dari hasil hipotesis pertama menunjukkan pengaruh path coefficients sebesar 0,5 , sedangkan nilai signifikan pada pengujian sebesar 5,5> 1,96 yang artinya bahwa Budaya organisasi berpengaruh dan signifikan terhadap Motivasi. Hipotesis 1 diterima.

\section{The influence of organizational culture on increasing work motivation at the Islamic Center Bin Baz (ICBB) Yogyakarta}

It is clear that a sense of satisfaction can give birth to positive work behavior, full of enthusiasm, good result-oriented, totality in work, agility and so on. But unfortunately this explanation has not been seen evenly at the Bin Baz Islamic Center Islamic Boarding School (ICBB). For this reason, research is needed on the influence of organizational culture on increasing work motivation at the Bin Baz Islamic Center (ICBB) Yogyakarta. This study uses quantitative data analysis. The results showed that there was an influence of organizational culture on motivation. There is an influence of Organizational Culture on Motivation. From the results of the first hypothesis, it shows that the effect of path coefficients is 0.5 , while the significant value on the test is 5.5 $>1.96$ which means that organizational culture has a significant and significant effect on motivation. Hypothesis 1 is accepted.

This is an open-access article under the CC-BY-SA license.

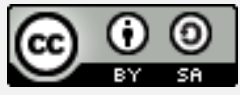

\section{Pendahuluan}

Cepatnya perubahan dalam segala bidang kehidupan, akibat dari adanya globalisasi serta perkembangan teknologi informasi menuntut kesadaran akan pentingnya kualitas Sumber Daya Manusia (SDM) yang merupakan salah satu respon dalam menyikapi perubahan 
tersebut. Sumber Daya Manusia (SDM) yang berkualitas sangat penting artinya bagi pembangunan suatu bangsa. Bahkan ketersediaan SDM berkualitas diyakini sebagai kunci utama keberhasilan pembangunan, untuk mewujudkan manusia yang berkualitas, dunia pendidikan dituntut untuk berperan aktif dalam meningkatkan kualitas SDM yang cerdas dan mandiri.

Pendidikan merupakan hal yang sangat penting dalam pengembangan sumber daya manusia. Melalui pendidikan, manusia dapat melepaskan diri dari keterbelakangan. Pendidikan juga mampu menanamkan kapasitas baru bagi manusia dalam mempelajari pengetahuan dan keterampilan baru, sehingga dapat diperoleh manusia yang produktif dan kompetitif. Menjadi tugas yang cukup berat bagi lembaga-lembaga pendidikan baik yang berbasis agama islam maupun umum untuk dapat menciptakan sumber daya manusia yang cakap, aktif, kreatif, dan inovatif yang mengarah pada kemajuan.

Dalam meningkatkan kualitas SDM yang baik terutama di lembaga pendidikan khususnya adalah guru, banyak faktor yang harus diperhatikan demi terwujudnya kualitas guru yang sesuai dengan kemajuan zaman. Salah satu yang menjadi perhatian peneliti adalah kepuasan guru dalam melaksanakan tugasnya, jika dalam mengajar atau mendidik santri seorang guru merasa puas dengan kerja nya diharapkan bisa memberikan efek yang besar bagi santri yang diajarkan sehingga terwujudlah tujuan pendidikan tersebut.

Guru memainkan peranan yang begitu besar di dalam sebuah negara. Tugas mereka bukan hanya sekedar memberikan pelajaran seperti yang terkandung di dalam garis besar pengajaran dalam kurikulum formal, malah meliputi seluruh aspek kehidupan yang lain mungkin tidak tercantum dalam mata pelajaran secara nyata, tetapi meliputi pelajaranpelajaran yang terkandung dalam kurikulum yang tersembunyi dalam sistem pendidikan negara. Kemajuan suatu bangsa punya kaitan erat dengan pendidikan.Pendidikan di sini bukan sekedar sebagai media (perantara) dalam menyampaikan kebudayaan dari generasi kegenerasi, melainkan suatu proses yang diharapkan akan dapat mengubah dan mengembangkan kehidupan berbangsa yang baik. Bagi suatu bangsa yang sedang membangun terlebih-lebih bagi keberlangsungan hidup bangsa di tengah-tengah lintasan perjalanan zaman dengan teknologi yang kian canggih. Semakin akurat para guru melaksanakan fungsinya, semakin terjamin, tercipta, dan terbinanya kesiapan dan keandalan sebagai manusia pembangunan. Oleh karena itu peningkatan kepuasan kerja yang diperoleh para guru akan mendorong guru untuk melaksanakan fungsinya sebaik mungkin.

Adanya fenomena mengenai penurunan kinerja guru, hal ini dapat terlihat dari guru yang mangkir dari tugas, guru yang mengajar saja tetapi fungsi mendidiknya berkurang. Sebagaimana pernah disinggung oleh Menteri Pendidikan Nasional: "akhir-akhir ini jumlah tenaga guru semakin sedikit, sebaliknya jumlah pengajar terus membengkak". Menurut Menteri Pendidikan Nasional dalam sambutan pelantikan rektor Universitas Surabaya (UNESA) di Surabaya mengatakan : "Indonesia saat ini minus tenaga guru, yang banyak adalah tenaga pengajar. Dia bekerja per jam, dan setiap jam minta bayaran”. Guru menurut Malik Fadjar, lebih dari sekedar pengajar.

Peningkatkan mutu pendidikan secara formal aspek guru mempunyai peranan penting dalam mewujudkannya, disamping aspek lainnya seperti sarana/prasarana, kurikulum, siswa, manajemen, dan pengadaan buku. Guru merupakan kunci keberhasilan pendidikan, sebab inti dari kegiatan pendidikan adalah belajar mengajar yang memerlukan peran dari guru di dalamnya. Berdasarkan hasil studi di negara-negara berkembang, guru memberikan sumbangan dalam prestasi belajar siswa (36\%), selanjutnya manajemen (23\%), waktu belajar (22\%), dan sarana fisik (19\%). Aspek yang berkaitan dengan guru adalah menyangkut citra/mutu guru dan kesejahteraan.

Sementara itu Tilaar menyatakan: "peningkatan kualitas pendidikan tergantung banyak hal, terutama mutu gurunya". Dengan demikian jelaslah bahwa keberhasilan pendidikan yang terutama adalah faktor guru sebagai tenaga pendidikan yang profesional. Salah satu hal yang 
patut dipertimbangkan adalah bagaimana upaya untuk meningkatkan kualitas guru adalah dengan cara meningkatkan kepuasan kerjanya, sebab dengan kepuasan guru yang meningkat maka guru akan berusaha untuk meningkatkan profesi dan mutunya dengan demikian diharapkan keberhasilan pendidikan akan tercapai. Kepuasan kerja guru itu bisa dilaksanakan dengan beberapa cara diantaranya adalah organisasi dapat membuat iklim organisasi yang berpihak pada kesejahteraan guru, terbuka dan menekankan pada prestasi, bisa pula kepuasan ditingkatkan menggunakan faktor motivasi terutama motivasi berprestasi guru, karena hal tugas guru menyangkut dengan keberhasilan siswa yang merupakan keberhasilan pendidikan. Pada tahun 1980-an masyarakat, kalangan akademisi, organisasi profesi dan pemerintah Amerika serikat secara serempak bertanya: "dari titik mana peningkatan mutu pendidikan Amerika dimulai?". Setelah dilakukan kajian mendalam dan luas tentang penentu-penentu mutu pendidikan, akhirnya mereka sepakat, langkah itu mesti dimulai dengan meningkatkan kesejahteraan guru. Keadaan di Amerika Serikat memang berbeda dengan dinegaranegara Eropa meskipun gaji guru telah dinaikkan, dibandingkan dengan karyawan pada profesi lain dengan tingkat pendidikan yang sama, gaji guru tetap lebih kecil.

Di Indonesia, rata-rata gaji guru sama besar bahkan lebih kecil dari gaji pekerja pabrik berpendidikan SD.

Peneliti juga memperhatikan adanya faktor-faktor yang bisa mempengaruhi kepuasan kerja guru di pesantren Islamic Center Bin Baz (ICBB) yaitu motivasi seorang guru dalam melaksanakan tugasnya, banyak dari ilmuan yang mengartikan motivasi dalam berbagai pandangan banyak fenomena yang terjadi yang mengarahkan bahwa kepuasan kerja dapat dipengaruhi oleh motivasi, sebagaimana penelitian yang di lakukan oleh Suhas (2009) bahwasanya, kepuasan kerja mempunyai pengaruh positif terhadap motivasi.

Suatu lembaga pendidikan dalam hal ini adalah Pondok Pesantren Islamic Center Bin Baz (ICBB) adalah lembaga pendidikan yang menyelenggarakan pengajaran mulai dari tingkat PAUD, TK, SD, SMP dan SMA yang berbasis agama islam tentunya menyadari akan pentingnya memiliki tenaga pengajar yang profesioanl, melihat tenaga pengajar merupakan icon penting dalam sebuah pendidikan yang jika tanpa memiliki guru yang berkualitas atau tidak kompeten akan menuai kegagalan dalam mencapai visi dan misi yang telah ditetapkan, kendatipun telah memiliki tenaga pengajar yang berkualitas, akan tetapi tanpa pengelolaan secara optimal tentu kontribusi terhadap organisasi akan jauh dari harapan. Sebagaimana yang dikemukakan oleh Veithzal Rifai (2005:1) bahwa keberadaan SDM memiliki peranan strategis dalam menjalankan berbagai fungsi manajemen sebuah institusi atau organisasi, baik sebagai penanggung jawab kebijakan dalam merumuskan perencanaan strategis, mengorganisasikan, pelaksanaan hingga pengendalian.

Pondok Pesantren Islamic Center Bin Baz (ICBB) adalah lembaga pendidikan di bawah naungan Yayasan Majelis At-Turots Al-Islamy Yogyakarta. Pondok pesantren ini sudah dirintis sejak tahun 1993 dengan nama Ma'had Tahfizhul Quran. Pada tahun 1996 kegiatan yang sebelumnya berlokasi di Sedan, Sariharjo, Ngaglik, Sleman dipindah ke Ma'had Jamilurrahman yang beralamat di Glondong Sawo Banguntapan Bantul. Seiring dengan selesainya pembangunan lokal kelas dan asrama di Karanggayam, Sitimulyo, Piyungan, Bantul pada tahun 2000, kegiatan Ma'had Tahfizhul Quran dipindah dari Ma'had Jamilurrahman ke lokasi baru ini. Di sinilah mulai digunakan nama Islamic Centre Bin Baz dan diselenggarakan pendidikan diniyah islamiyah dan pendidikan umum secara terpadu.

Tiga tahun kemudian, tepatnya pada tahun 2003, ICBB ditetapkan oleh Depag sebagai penyelenggara program wajib belajar pendidikan dasar 9 tahun (Wajar Dikdas). Tingkat SD disebut dengan Salafiyah Ula (SU) dan tingkat SMP disebut Salafiyah Wustha (SW). Dengan program ini lulusan SU dan SW ICBB, selain mendapatkan ijazah pondok, akan mendapatkan ijazah resmi dari pemerintah.

Terhitung sejak 2010, jenjang pendidikan setingkat SMA yaitu Madrasah Aliyah ICBB telah menjadi lembaga pendidikan formal. Dan pada tahun 2012 telah mendapatkan 
akreditasi peringkat A dari Badan Akreditasi Nasional Sekolah/Madrasah untuk program IPA dan Keagamaan. Selain itu satu tahun sebelumnya yaitu pada tahun 2011 Ijazah pondok mendapatkan mu'adalah (Akreditasi) dari Universitas Islam Madinah, Saudi Arabia (dokumentasi ICBB).

Pondok pesantren Islamic Center Bin Baz (ICBB) adalah pesantren bermanhaj salaf pertama di yogyakarta yang mengusung tiga keunggulan yaitu tahfidzulqur'an, pelajaran umum, dan pelajaran diniyah. Setiap alumni pondok pesantren tersebut insya Allah menjadi hafidz atau hafidzoh dan mempunyai basis ilmu agama islam serta ilmu umum yang mengikuti Depag dimana jenjang MA mempunyai dua jurusan yaitu agama dan IPA sehingga santriwati bisa bersaing dengan lulusan dari luar. Dengan tiga keunggulan inilah dibutuhkan guru-guru yang berjiwa besar dan berpengalaman sehingga bisa memotivasi santri dalam menjalankan kegiatankegiatan di pesantren dengan baik.

Mengingat pentingnya peranan SDM dalam hal ini adalah guru sebagai salah satu faktor penentu bagi keberhasilan atau kegagalan lembaga pendidikan dalam mencapai tujuan, untuk mencapai sasaran dan tujuan strategi lembaga pendidikan dibutuhkan tenaga pengajar atau sumber daya manusia yang unggul, andal, dan visioner, serta mampu menyesuaikan diri searah dan sejalan dengan visi misi serta tujuan organisasi.

Tidak dapat dipungkiri bahwa peranan guru yang profesional dan berkinerja tinggi lah yang kemudian dapat mencapai tujuan-tujuan sebagaimana tersebut di atas. Oleh karenanya keberadaan guru tidak dapat dipandang sebelah mata oleh lembaga atau instansi yang menggunakannya, perlu ada sinergisitas dan tindakan serius dari lembaga terkait untuk terus mengembangkan kinerja guru. Sebagaimana tertuang dalam UU nomor 14 tahun 2005 yang menyatakan bahwa berapapun besar investasi yang ditanamkan untuk memperbaiki mutu pendidikan, tanpa kehadiran guru dan dosen yang kompeten, profesional, bermartabat, dan sejahtera dapat dipastikan tidak akan tercapai tujuan yang diharapkan (UU No.14 tahun 2005).

Guru adalah sebuah profesi sebagaimana profesi lainnya yang merujuk pada pekerjaannya atau jabatan yang menuntut kepada keahlian, tanggung jawab, dan kesetiaan. Sehingga, menciptakan guru yang profesional yang bisa menjadi panutan yang baik bagi para siswa.

Salah satu upaya yang dapat dilakukan untuk meningkatkan profesionalitas atau kinerja guru adalah dengan membangun rasa kepuasan. Mengingat kepuasan kerja merupakan faktor yang sangat penting untuk mendapatkan kerja yang optimal, ketika seorang merasakan kepuasan dalam bekerja, ia akan berusaha semaksimal mungkin dengan segenap kemampuannya, untuk menyelesaikan tugas pekerjaannya.

Robbins (2003:30), menjelaskan kepuasan kerja adalah suatu sikap umum terhadap pekerjaan seseorang, selisih antara banyaknya ganjaran yang diterima seorang pekerja dan banyaknya yang mereka yakini seharusnya mereka terima. Kepuasan terjadi apabila kebutuhan-kebutuhan individu sudah terpenuhi, dan terkait dengan derajat kesukaan atau ketidaksukaan, dikaitkan dengan karyawan. Adapun sikap umum yang dimiliki oleh karyawan yang erat kaitannya dengan imbalan-imbalan yang mereka yakini, akan mereka terima setelah melakukan sebuah pengorbanan.

Dari paparan tersebut jelas bahwa secara eksplisit kepuasan mengajar seorang guru dapat tercapai apabila segala hal yang berkaitan dengan kebutuhannya dapat terpenuhi sesuai dengan karakteristiknya masing-masing. Selain itu, kepuasan kerja juga menuntut adanya perlakuan lebih. Artinya perlakuan instansi yang dapat menjadikan seorang guru dapat merasa dihargai dan diberikan dorongan untuk dapat berkarya. Misalnya diberikan promosi atau jabatan struktural.

Lebih lanjut penelitian Faheem Ghazanfar (2011) membuktikan bahwa kepuasan kerja dapat melahirkan tingkat kerja yang tidak diduga, para pegawai akan menunjukkan sikap loyal dan peduli terhadap instansi, bahkan pegawai merasa bangga telah dapat bekerja pada

Roidah Lina et.al (Pengaruh budaya organisasi...) 
instansi tersebut.

Penjelasan tersebut nampak jelas bahwa rasa kepuasan mampu melahirkan perilaku kerja yang positif, penuh semangat, berorientasi pada hasil yang baik, totalitas dalam bekerja, cekatan dan lain sebagainya. Namun sayangnya paparan tersebut belum terlihat secara merata di Pondok Pesantren Islamic Center Bin Baz (ICBB). Berdasarkan hasil observasi yang dilakukan oleh penulis masih terdapat guru yang tidak masuk kelas tanpa alasan, banyaknya tuntutan mengenai kesejahteraan namun tidak diimbangi dengan etos kerja yang baik, dan bahkan antar guru masih saling melempar tanggung jawab pekerjaan. Misalnya pada saat penyelenggaraan ujian, masih banyak para guru yang tidak mau menertibkan peserta didik yang mereka ampu.

\section{Metode}

Penelitian ini digolongkan ke dalam jenis penelitian lapangan (field research), yaitu dalam proses perolehan data sesuai dengan sasaran atau masalah penelitian yang diperlukan sebuah informasi yang selengkap- lengkapnya atau sedalamdalamnya mengenai gejala-gejala yang ada dalam lingkup obyek penelitian. Dari gejala-gejala penelitian yang ada dalam penelitian ini bukanlah satu-satunya yang berdiri, melainkan saling berkaitan antara satu sama lain dalam kesatuan yang menyeluruh yang biasanya dikenal dengan pendekatan ${ }^{1}$. Penelitian ini menggunakan analisis data kuantitatif.

Sebelum hasil penelitian disajikan akan dijelaskan terlebih dahulu karakteristik responden yang meliputi jenis kelamin, usia, pendidikan terakhir. Dalam penelitian ini terdiri dari 100 responden yang terbagi menjadi tiga jenjang pendidikan yaitu guru SMA, SW, SU. Untuk mendapatkan gambaran responden, berikut adalah karakteristik responden.

Karakteristik Responden Berdasarkan Jenis Kelamin;

\begin{tabular}{|c|c|c|}
\hline $\begin{array}{c}\text { Jenis } \\
\text { kelamin }\end{array}$ & frequency & Percent \\
\hline Pria & 52 & 52 \\
\hline Wanita & 48 & 48 \\
\hline Total & 100 & 100 \\
\hline
\end{tabular}

Merupakan karakteristik responden berdasarkan usia pegawai pondok pesantren Islamic Centre Bin Baz;

\begin{tabular}{|c|c|c|}
\hline Usia & Frequency & Percent \\
\hline $20-30$ tahun & 68 & 68 \\
\hline $31-40$ tahun & 18 & 18 \\
\hline $41-50$ tahun & 13 & 13 \\
\hline $51-60$ tahun & 1 & 1 \\
\hline Total & 100 & 100 \\
\hline
\end{tabular}

Karakteristik responden berdasarkan pendidikan terakhir pegawai pondok pesantren Islamic Centre Bin Baz. 


\begin{tabular}{|l|l|l|l|l|l|}
\hline Pendidikan & SMA & SW & SU & Frequency & Percent \\
\hline SMA & 6 & 5 & 19 & 30 & 30 \\
\hline S1 & 39 & 16 & 6 & 61 & 61 \\
\hline S2 & 6 & 0 & 0 & 6 & 6 \\
\hline D2 & 0 & 2 & 1 & 3 & 3 \\
\hline TOTAL & 51 & 23 & 26 & 100 & 100 \\
\hline
\end{tabular}

Dari tabel tersebut telah terlihat banyaknya guru yang dipersentasikan untuk lulusan SMA sebanyak 30 guru yang mayoritas guru di jenjang SU, sedangkan lulusan SI sebanyak 61 guru dan yang terbanyak di jenjang SMA sedangkan untuk lulusan D2 berjumlah 3 guru dan S2 berjumlah 6 guru.

\section{Hasil dan Pembahasan}

\section{Gambaran Umum Islamic Center Bin Baz (ICBB)}

Hasil dan Pembahasan dapat disajikan dalam subbab. Membahas secara jelas pokok bahasan sesuai dengan masalah, tujuan penelitian, dan teori yang digunakan.

Pondok Pesantren Islamic Centre Bin Baz (ICBB) adalah lembaga pendidikan di bawah naungan Yayasan Majelis At-Turots Al-Islamy Yogyakarta. Pondok pesantren ini sudah dirintis sejak tahun 1993 dengan nama Ma'had Tahfizhul Qur'an. Pada tahun 1996 kegiatan yang sebelumnya berlokasi di Sedan, Sariharjo, Ngaglik, Sleman dipindah ke Ma'had Jamilurrahman yang beralamat di Glondong Sawo, Banguntapan, Bantul. Seiring dengan selesainya pembangunan lokal kelas dan asrama di Karanggayam, Sitimulyo, Piyungan, Bantul pada tahun 2000, kegiatan Ma'had Tahfizhul Qur'an dipindah dari Ma'had Jamilurrahman ke lokasi baru ini. Di sinilah mulai digunakan nama Pondok Pesantren Islamic Centre Bin Baz dan diselenggarakan pendidikan diniyah islamiyah dan pendidikan umum secara terpadu.

Tiga tahun kemudian, tepatnya pada tahun 2003, Pondok Pesantren Islamic Centre Bin Baz (ICBB) ditetapkan oleh Departemen Agama (Depag) sebagai penyelenggara program wajib belajar pendidikan dasar 9 tahun (Wajar Dikdas). Tingkat SD disebut dengan Salafiyah Ula (SU) dan tingkat SMP disebut Salafiyah Wustha (SW). Dengan program ini lulusan SU dan SW ICBB, selain mendapatkan ijazah pondok pesantren, akan mendapatkan ijazah resmi dari pemerintah.

Terhitung sejak 2010, jenjang pendidikan setingkat SMA yaitu Madrasah Aliyah ICBB telah menjadi lembaga pendidikan formal. Dan pada tahun 2012 telah mendapatkan akreditasi peringkat A dari Badan Akreditasi Nasional Sekolah/Madrasah untuk program IPA dan Keagamaan. Selain itu satu tahun sebelumnya yaitu pada tahun 2011 Ijazah pondok mendapatkan mu'adalah

(Akreditasi) dari Universitas Islam Madinah, Saudi Arabia. Dalam bidang Tahfizh AlQur'an, pada tahun 2011 ICBB membuka Ma'had Tahfizh khusus untuk mempersiapkan calon pengajar tahfizh yang bersanad dan berijazah.

Visi Pondok Pesantren Islamic Centre Bin Baz (ICBB) adalah menjadi lembaga pendidikan bertaraf internasional yang bermanhaj salaf dalam berakidah, bermuamalah dan berakhlak mulia. Adapun Misi Pondok Pesantren Islamic Centre Bin Baz (ICBB) adalah mencetak 
generasi rabbani yang berpegang teguh kepada AlQur'an dan As-Sunnah sesuai pemahaman Salafus Shalih, mendidik generasi penghafal Al-Quran yang memahami pokok-pokok agama dan beradap kepada Allah, Rasul-Nya, orang tua, sesama manusia dan makhluk secara umum, serta mampu berbahasa Arab baik tulisan, bacaan, maupun percakapan, menyelenggarakan pendidikan resmi dengan kurikulum diniyah dari Timur Tengah dan kurikulum umum nasional yang mendapatkan 2 ijazah yang diakui baik oleh Pemerintah maupun lembaga pendidikan di Timur Tengah, dan menciptakan suasana dan lingkungan yang berbahasa Arab dan Islami di lingkungan Islamic Centre Bin Baz.

Jenjang Pendidikan di Pondok Pesantren Islamic Centre Bin Baz (ICBB) yaitu

TPA, PAUD, TK dan KB, Salafiyah Ula (SU), Salafiyah Wustha (SW), I'dad Lughowi/Takhosus, Program penyiapan Bahasa Arab bagi para calon santri Madrasah Aliyah yang berasal dari luar Islamic Centre Bin Baz, lama pendidikan 1 tahun, Madrasah Aliyah, Ma'had I'dad Mu'allimil Qur'an, serta Pendidikan penyiapan pengajar Al-Quran (khusus putra) dengan lama pendidikan 2 tahun (berijazah dan bersanad).

Kegiatan pendidikan di ICBB ditangani oleh para pendidik yang merupakan alumni Perguruan Tinggi di Saudi Arabia, Mesir, Pakistan, LIPIA, Universitasuniversitas ternama di Indonesia, alumni Pondok Pesantren Salaf, dan lain-lain. Dari tahun ke tahun ICBB senantiasa melakukan peningkatan mutu pendidik, salah satunya melalui workshop-workshop kependidikan yang diselenggarakan secara rutin. Dalam bidang Tahfizh dan Qiro'atul Qur'an, santri ICBB dibimbing oleh para pengajar yang memiliki Sanad dan Ijazah.

Fasilitas di Pondok Pesantren Islamic Centre Bin Baz (ICBB) antara lain Perpustakaan, laboratorium IPA, komputer, multimedia dan Bahasa, Minimarket di dalam lingkungan pondok, Fasilitas olahraga: kolam renang, lapangan futsal, basket, sepak takraw, volley \& bulu tangkis, Lingkungan pondok yang bersih dan asri serta masyarakat yang kondusif, Perawatan di rumah sakit milik sendiri (RS At-Turots AlIslamy), dan SMS Centre dan Sistem Informasi Pondok berbasis Web untuk mengakses informasi nilai, SPP, kesehatan, presensi santri, dan Majalah Fatawa sebagai sarana informasi dan komunikasi antara wali santri dan pondok.

Target Lulus Salafiyah Ula yaitu Bisa membaca Al Qur'an, Hafal Al Qur'an minimal 6 (enam) juz dan minimal 15 Hadits, Hafal Tasrif Dasar (Tsulasi Mujarrad - istilah dan lughowi - , Dhamir), Mampu menulis tulisan Arab dengan kaidah bahasa Arab yang benar, Mengerti aqidah yang shahih, Mampu mempraktekkan ibadah praktis (Wudhu, Shalat, Puasa), dan Memiliki kebiasaan Akhlakul-Karimah dan adab-adab Islami (berbakti kepada orang tua, hormat kepada yang lebih tua, patuh kepada guru, sayang dan suka membantu teman/saudara, menyebarkan salam, baik dalam bertutur kata).

Target Lulus Salafiyah Wustha yaitu Hafal Al Qur'an minimal 5 (lima) juz secara mutqin dan minimal 30 Hadits, Bisa baca arab gundul, Mampu berbicara bahasa Arab dengan baik, Mampu menulis dengan kaidah bahasa Arab yang benar (kaidah imla'), Menguasai aqidah yang baik, Menguasai ibadah praktis, Memiliki Akhlakul-Karimah dan adab-adab Islami (berbakti kepada orang tua, hormat kepada yang lebih tua, patuh kepada guru, sayang dan suka membantu teman/saudara, menyebarkan salam, baik bertutur kata), serta komitmen dengan Sunnah, dan Lulus UAN.

Target Lulus Madrasah Aliyah yaitu Dapat melanjutkan ke Perguruan Tinggi di Timur Tengah, LIPIA, PTN/PTS Dalam Negeri, Hafal Al Qur'an minimal 10 juz secara mutqin dan minimal 60 hadits, Dapat memahami dan menjelaskan isi kitab arab gundul, Mampu membuat karya ilmiyah berbahasa arab, Mampu berbicara bahasa Arab dengan lancer, Memiliki Akhlakul-Karimah dan adab-adab Islami (berbakti kepada orang tua, hormat kepada yang lebih tua, patuh kepada guru, sayang dan suka membantu teman/saudara, menyebarkan salam, baik bertutur kata), serta komitmen dengan Sunnah, Siap bertugas/khidmat dimanapun ditempatkan, Siap dan mampu berceramah atau berkhutbah di masyarakat, dan Lulus UAN. Adapun kegiatan ekstrakurikuler antara lain Olah Raga dan Bela Diri Wushu, Komputer (Hardware \& Software), Tata Busana, Menyulam \& Keterampilan tangan, Tata Boga / Memasak, dan Jurnalistik. 


\section{Analisis Pengaruh Budaya Organisasi Terhadap Peningkatan Motivasi Kerja}

Variabel penelitian ini terdiri dari empat variabel yaitu kepuasan kerja guru, motivasi, budaya organisasi dan stres kerja. Setiap variabel akan mendeskripsikan berdasarkan dimensi dan indikatornya untuk mengetahui validitas konstruk, validitas diskriminan, composite reliabilty dan cronbach alpha dalam outer model sedangkan inner model akan diketahui R square, path coefisien.

Penilaian outer atau measurement model tersebut mengunakan software Pls 2.0. Teknik pengolahan data dengan mengunakan metode SEM berbasis partial least squart (PLS) memerlukan 2 tahap, yaitu :

Menilai Outer atau Measurement Model

Dalam teknik analisa data mengunakan Smart PLS, Outer Model menilai cenvergent validity, Discriminat validity dan composite reliability dan cronbach alpha. Model pengukuran ini mengunakan pengukuran reflektif dimana indikator dinilai berdasarkan kolerasi antara item score/componentst score yang diestimasi dengan sofware PLS. Ukuran reflektif dikatakan tinggi apabila berkolerasi lebih tinggi dari 0,70 dengan konstruk yang diukur.

a. Kepuasan Kerja Guru di Islamic Center Bin Baz (ICBB)

Elemen elemen kerja kepuasan kerja meliputi tipe kerja, rekan kerja, tunjangan, diperlakukan dengan hormat dan adil, keamanan kerja, peluang menyumbangkan gagasan, upah, pengakuan akan kinerja dan kesempatan untuk maju. Adapun pertanyaanpertanyaannya dalam di lihat di lampiran yang terdiri dari 10 pertanyaan pada kolom 1-10.

Berikut ini gambaran uji fist order, yaitu pengaruh dimensi terhadap indikator untuk melihat convergent validity dari masing-masing indikator terhadap dimensi, dan hasil uji second order untuk melihat convergen validity dari masing-masing indikator terhadap kepuasan kerja guru.

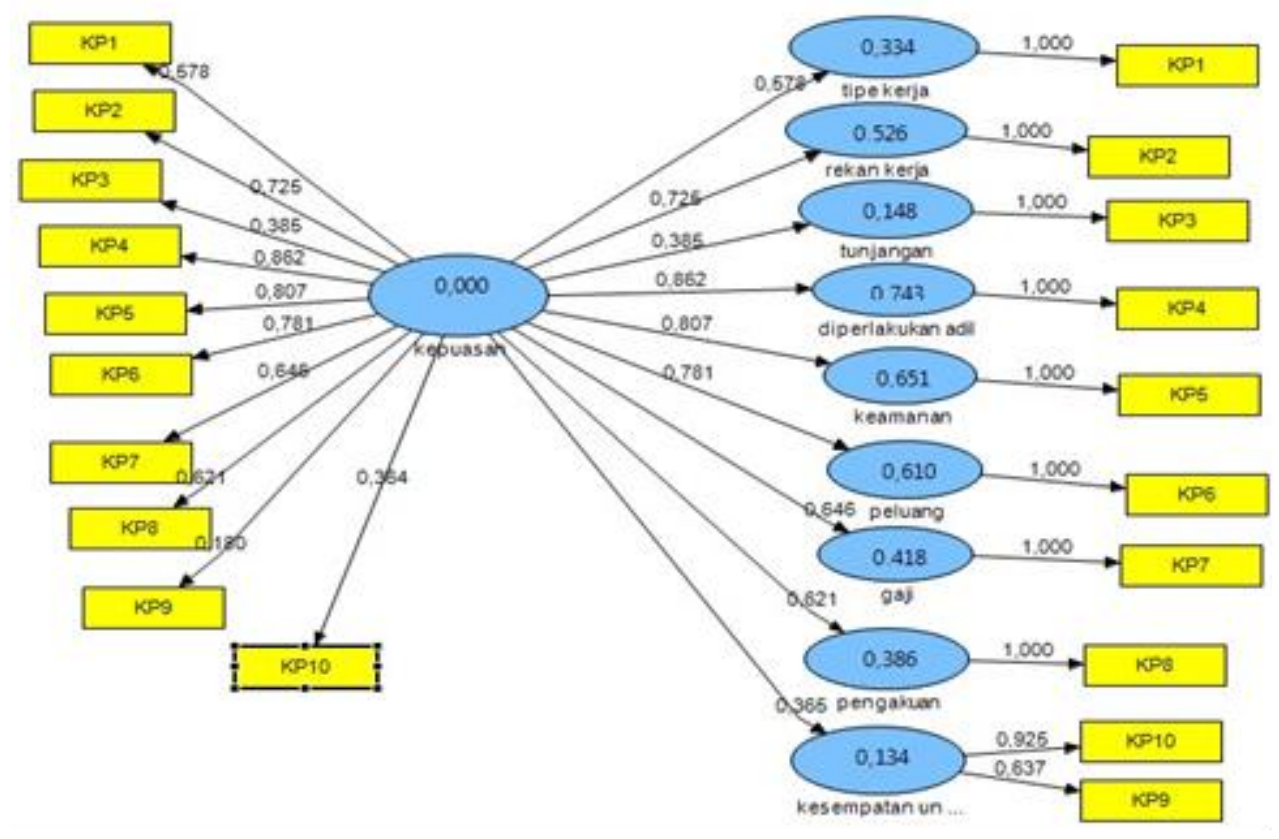


Uji Algoritma Kepuasan sebagai berikut;

\begin{tabular}{|l|l|l|l|l|}
\hline & AVE & Composite Reliability & R Square & Cronbachs Alpha \\
\hline diperlakukan adil & 1,000000 & 1,000000 & 0,742636 & 1,000000 \\
\hline Gaji & 1,000000 & 1,000000 & 0,417523 & 1,000000 \\
\hline Keamanan & 1,000000 & 1,000000 & 0,651111 & 1,000000 \\
\hline Kepuasan & 0,398037 & 0,854635 & & 0,812745 \\
\hline kesempatan un maju & 0,630064 & 0,767124 & 0,133528 & 0,455410 \\
\hline Peluang & 1,000000 & 1,000000 & 0,610471 & 1,000000 \\
\hline Pengakuan & 1,000000 & 1,000000 & 0,385716 & 1,000000 \\
\hline rekan kerja & 1,000000 & 1,000000 & 0,526055 & 1,000000 \\
\hline tipe kerja & 1,000000 & 1,000000 & 0,333819 & 1,000000 \\
\hline Tunjangan & 1,000000 & 1,000000 & 0,148251 & 1,000000 \\
\hline
\end{tabular}

Dari tabel diatas menunjukkan masing-masing nilai validitas konstuk (AVE $>0,5$ ), composit Reliability $(>0,80)$, dan chronbach Alpha $(>0,70)$ semua indikator tersebut memenuhi syarat validitas dan reliabilitas yang baik.

Boostrapping Konstruk Outer Model Kepuasan ;

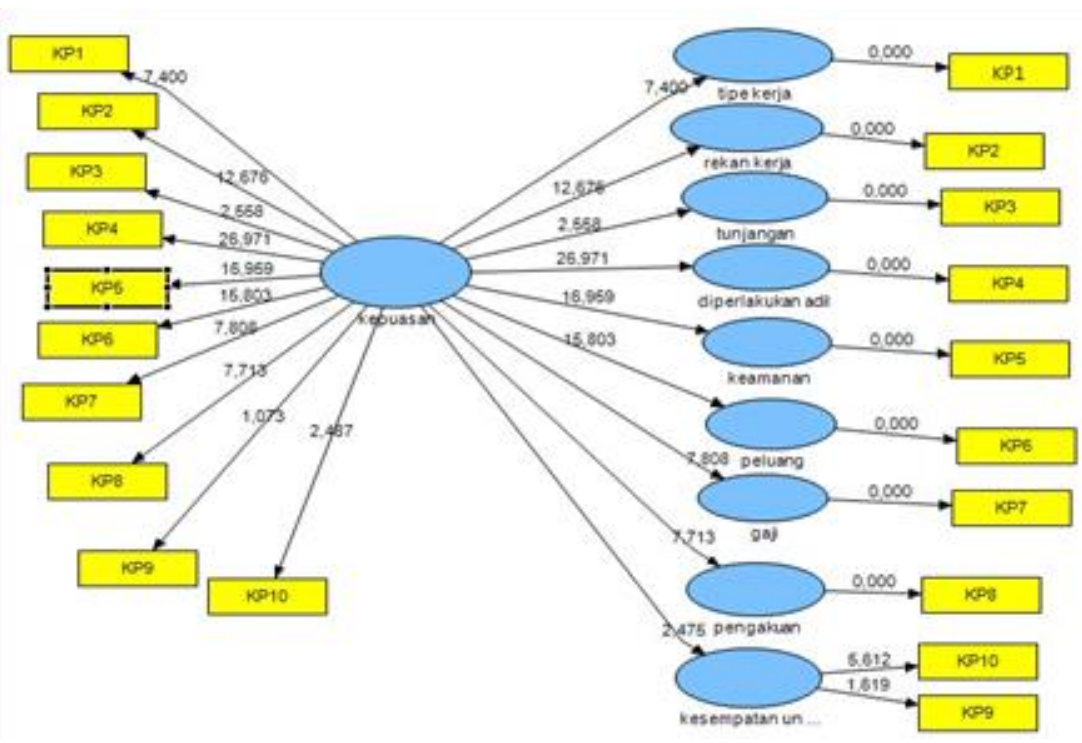


Path Coefficients (Mean, STDEV, T-Values) kepuasan kerja;

\begin{tabular}{|c|c|c|c|c|c|}
\hline & $\begin{array}{l}\text { Original } \\
\text { Sample } \\
(0)\end{array}$ & $\begin{array}{l}\text { Sample } \\
\text { Mean (M) }\end{array}$ & $\begin{array}{l}\text { Standard } \\
\text { Deviation } \\
\text { (STDEV) }\end{array}$ & $\begin{array}{l}\text { Standard } \\
\text { Error } \\
\text { (STERR) }\end{array}$ & $\begin{array}{l}\text { T Statistics } \\
(\mid \mathrm{O} / \text { STERR } \mid)\end{array}$ \\
\hline $\begin{array}{l}\text { kepuasan -> } \\
\text { diperlakukan } \\
\text { adil }\end{array}$ & 0,861763 & 0,860821 & 0,031951 & 0,031951 & 26,971443 \\
\hline $\begin{array}{l}\text { kepuasan -> } \\
\text { gaji }\end{array}$ & 0,646160 & 0,649867 & 0,082751 & 0,082751 & 7,808451 \\
\hline $\begin{array}{l}\text { kepuasan -> } \\
\text { keamanan }\end{array}$ & 0,806914 & 0,806705 & 0,047580 & 0,047580 & 16,959093 \\
\hline $\begin{array}{l}\text { kepuasan -> } \\
\text { kesempatan un } \\
\text { maju }\end{array}$ & 0,365414 & 0,378412 & 0,147656 & 0,147656 & 2,474777 \\
\hline $\begin{array}{l}\text { kepuasan -> } \\
\text { peluang }\end{array}$ & 0,781327 & 0,781438 & 0,049443 & 0,049443 & 15,802668 \\
\hline $\begin{array}{l}\text { kepuasan -> } \\
\text { pengakuan }\end{array}$ & 0,621060 & 0,616994 & 0,080524 & 0,080524 & 7,712745 \\
\hline $\begin{array}{l}\text { kepuasan -> } \\
\text { rekan kerja }\end{array}$ & 0,725297 & 0,723674 & 0,057216 & 0,057216 & 12,676364 \\
\hline
\end{tabular}

Lanjutan Path Coefficients (Mean, STDEV, T-Values)kepuasan kerja

\begin{tabular}{|l|l|l|l|l|l|}
\hline & $\begin{array}{l}\text { Original } \\
\text { Sample (O) }\end{array}$ & $\begin{array}{l}\text { Sample } \\
\text { Mean (M) }\end{array}$ & $\begin{array}{l}\text { Standard } \\
\text { Deviation } \\
\text { (STDEV) }\end{array}$ & $\begin{array}{l}\text { Standard } \\
\text { Error } \\
\text { (STERR) }\end{array}$ & $\begin{array}{l}\text { T Statistics } \\
\text { (|O/STERR|) }\end{array}$ \\
\hline $\begin{array}{l}\text { kepuasan -> tipe } \\
\text { kerja }\end{array}$ & 0,577771 & 0,574664 & 0,078074 & 0,078074 & 7,400291 \\
\hline $\begin{array}{l}\text { kepuasan -> } \\
\text { tunjangan }\end{array}$ & 0,385034 & 0,368948 & 0,150544 & 0,150544 & 2,557614 \\
\hline
\end{tabular}


Path cofficient dan t statistic menunjukkan dimensi kepuasan bahwa ada dua dimensi yang dibawah 0,05 yaitu kepuasan kerja terhadap kesempatan untuk maju dengan nilai 0,36 dan kepuasan kerja terhadap tunjang dengan nilai 0,38 dan ini menunjukkan bahwa kepuasan kerja tidak berpengaruh pada kesempatan untuk maju dan tunjangan sedangkan kepuasan kerja terdapat dimensi yang lain berpengaruh dan semua signifikan diatas 0,05 dan nilai $\mathrm{p}$ diatas 1,96 .

b. Motivasi di Islamic center Bin Baz (ICBB)

Dimensi motivasi adalah (1) kebutuhan fisiologi.(2) kebutuhan rasa aman.(3) kebutuhan social.(4) kebutuhan akan penghargaan.(5) kebutuhan aktualisasi diri. Kelima dimensi ini mempunyai 10 indikator yang terdiri dari masing-masing dimensi.

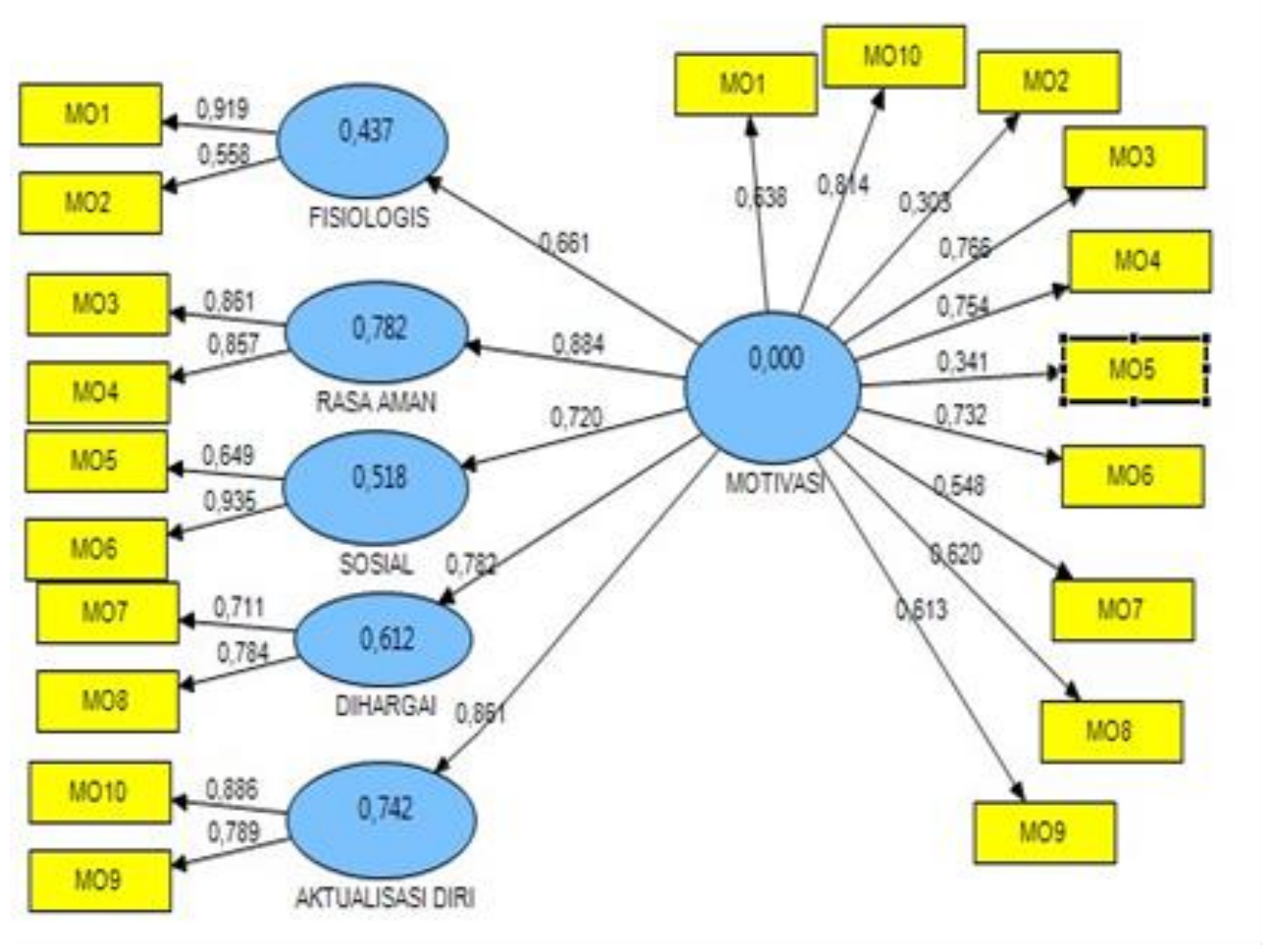

Hasil Uji Algoritma Motivasi

\begin{tabular}{|l|l|l|l|l|}
\hline & AVE & $\begin{array}{l}\text { Composite } \\
\text { Reliability }\end{array}$ & $\begin{array}{l}\text { R } \\
\text { Square }\end{array}$ & $\begin{array}{l}\text { Cronbachs } \\
\text { Alpha }\end{array}$ \\
\hline $\begin{array}{l}\text { AKTUALISASI } \\
\text { DIRI }\end{array}$ & 0,704190 & 0,825938 & $\begin{array}{l}0,74204 \\
2\end{array}$ & 0,586685 \\
\hline DIHARGAI & 0,559541 & 0,717089 & $\begin{array}{l}0,61189 \\
6\end{array}$ & 0,213975 \\
\hline FISIOLOGIS & 0,577570 & 0,720668 & $\begin{array}{l}0,43677 \\
5\end{array}$ & 0,311840 \\
\hline
\end{tabular}




\begin{tabular}{|l|l|l|l|l|}
\hline MOTIVASI & 0,402837 & 0,862816 & & 0,818335 \\
\hline RASA AMAN & 0,737779 & 0,849105 & $\begin{array}{l}0,78230 \\
4\end{array}$ & 0,644600 \\
\hline SOSIAL & 0,648236 & 0,781159 & $\begin{array}{l}0,51791 \\
8\end{array}$ & 0,505470 \\
\hline
\end{tabular}

Dari tabel 4.7 menunjukkan masing-masing nilai validitas konstuk (AVE $>0,5)$, composit Reliability $(>0,80)$, dan chronbach Alpha $(>0,70)$ semua indikator tersebut memenuhi syarat validitas dan reliabilitas yang baik.

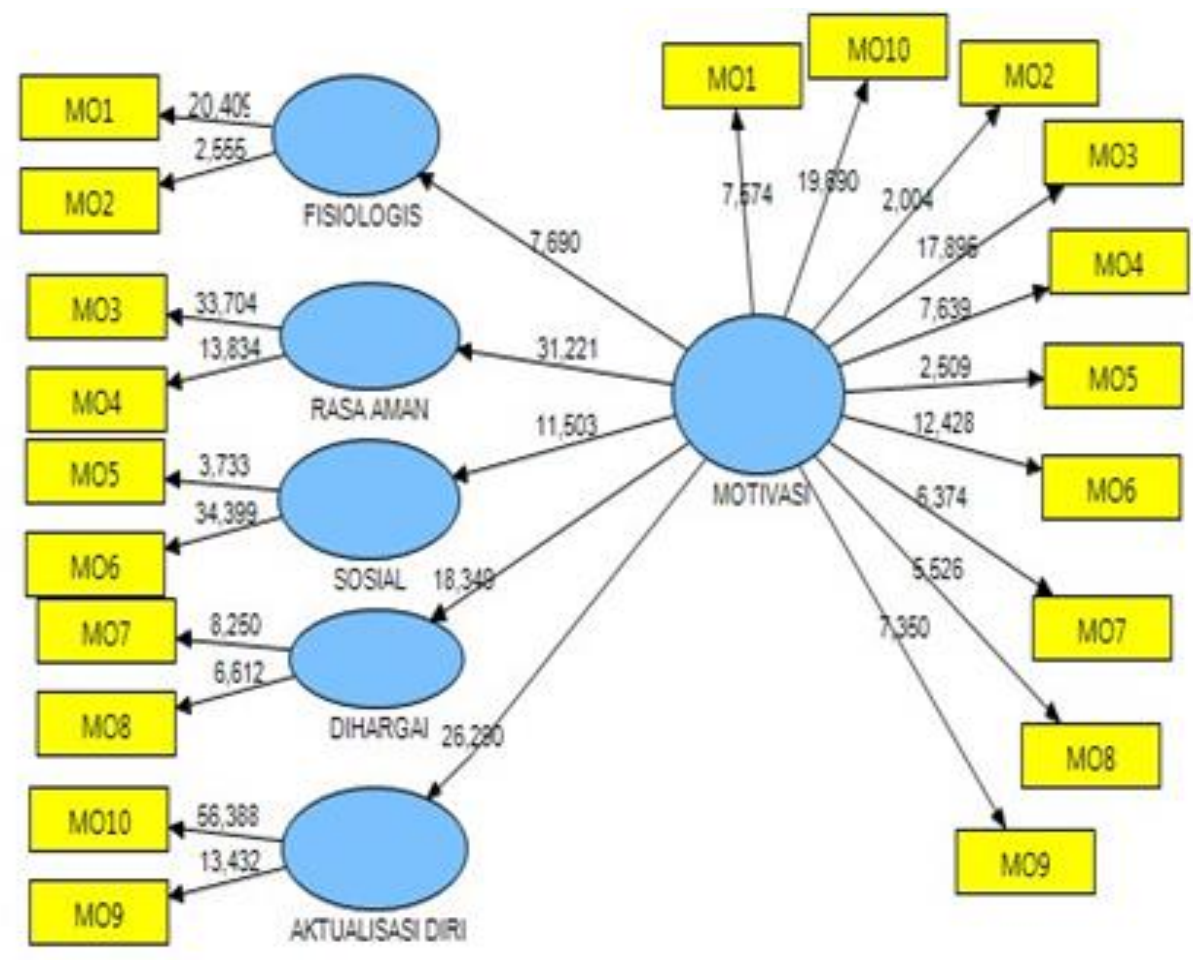

Path Coefficients (Mean, STDEV, T-Values) Motivasi

\begin{tabular}{|l|l|l|l|l|l|}
\hline & $\begin{array}{l}\text { Original } \\
\text { Sample } \\
(0)\end{array}$ & $\begin{array}{l}\text { Sample } \\
\text { Mean (M) }\end{array}$ & $\begin{array}{l}\text { Standard } \\
\text { Deviation } \\
\text { (STDEV) }\end{array}$ & $\begin{array}{l}\text { Standard } \\
\text { Error } \\
\text { (STERR) }\end{array}$ & $\begin{array}{l}\text { T Statistics } \\
\text { (|O/STERR|) }\end{array}$ \\
\hline $\begin{array}{l}\text { MOTIVASI -> } \\
\text { AKTUALISASI } \\
\text { DIRI }\end{array}$ & 0,861419 & 0,862329 & 0,032766 & 0,032766 & 26,289720 \\
\hline
\end{tabular}




\begin{tabular}{|l|l|l|l|l|l|}
\hline $\begin{array}{l}\text { MOTIVASI -> } \\
\text { DIHARGAI }\end{array}$ & 0,782238 & 0,786400 & 0,042631 & 0,042631 & 18,348869 \\
\hline $\begin{array}{l}\text { MOTIVASI -> } \\
\text { FISIOLOGIS }\end{array}$ & 0,660889 & 0,664867 & 0,085941 & 0,085941 & 7,690020 \\
\hline $\begin{array}{l}\text { MOTIVASI -> } \\
\text { RASA AMAN }\end{array}$ & 0,884480 & 0,885542 & 0,028329 & 0,028329 & 31,221372 \\
\hline $\begin{array}{l}\text { MOTIVASI -> } \\
\text { SOSIAL }\end{array}$ & 0,719665 & 0,736139 & 0,062562 & 0,062562 & 11,503299 \\
\hline
\end{tabular}

Path coefisients dari tabel tersebut menunjukkan pengaruh antar motivasi terhadap dimensinya positif berpengaruh diatas 0,50 dan nilai t lebih besar dari 1,96.

c. Budaya organisasi di Islamic Center Bin Baz (ICBB)

Budaya organisasi yang yang diukur adalah : (1) Nilai-nilai organisasi, (2) Dukungan manajemen, (3) Sistem imbalan, (4) Toleransi dalam berbagi kesalahan sebagai peluang untuk belajar, (5) Orientasi pada rincian (detail) pekerjaan, (6) Orientasi pada tim. Keenam dimensi ini akan diukur dengan 13 indikator yang akan diukur melalui outer model dan inner model sehingga menghasilkan nilai validitas dan reabilitas serta Path coefisients antar variable laten.

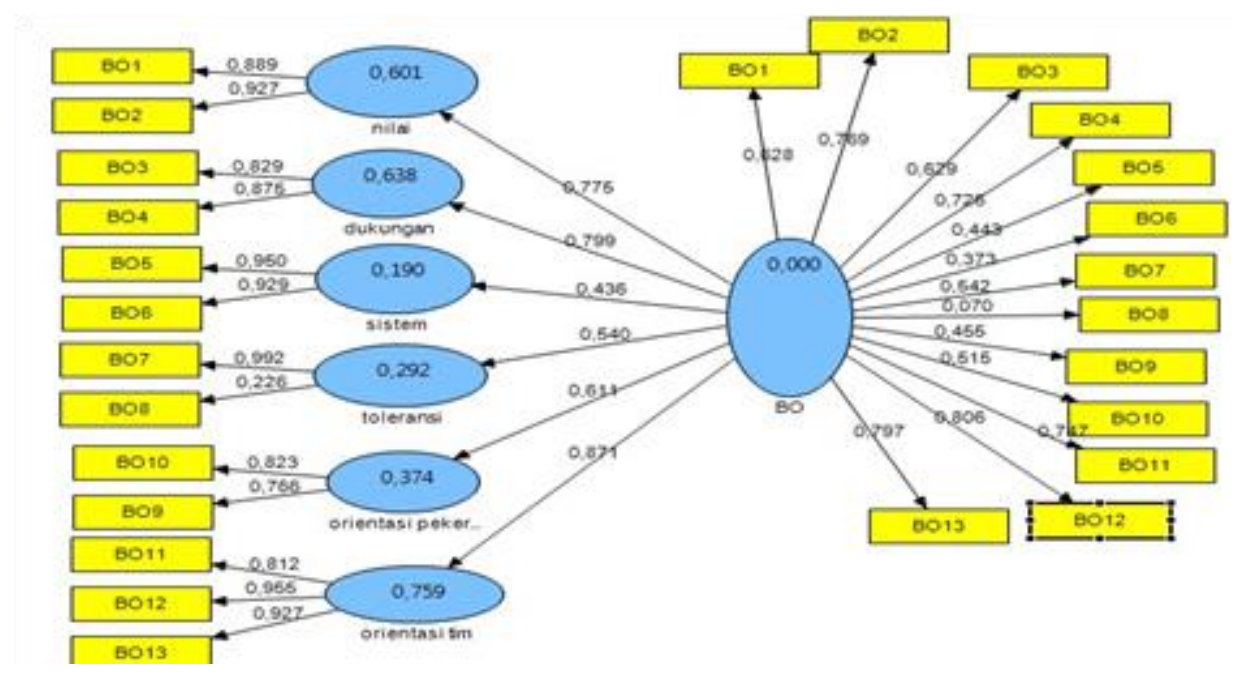

Uji Algoritma Budaya Organisasi 


\begin{tabular}{|l|l|l|l|l|}
\hline & AVE & Composite Reliability & R Square & Cronbachs Alpha \\
\hline BO & 0,373810 & 0,873610 & & 0,840424 \\
\hline Dukungan & 0,725763 & 0,840995 & 0,637708 & 0,623797 \\
\hline nilai & 0,825383 & 0,904301 & 0,601333 & 0,790474 \\
\hline orientasi pekerjaan & 0,632173 & 0,774411 & 0,373926 & 0,419653 \\
\hline orientasi tim & 0,810185 & 0,927242 & 0,759300 & 0,880042 \\
\hline Sistem & 0,883400 & 0,938083 & 0,190463 & 0,868958 \\
\hline Toleransi & 0,517592 & 0,605882 & 0,291558 & 0,184365 \\
\hline
\end{tabular}

Dari tabel diatas menunjukkan masing-masing nilai validitas konstuk (AVE >0,5), composit Reliability $(>0,80)$, dan chronbach Alpha $(>0,70)$. Path Coefficients (Mean, STDEV, T Values)

\begin{tabular}{|l|l|l|l|l|l|}
\hline & $\begin{array}{l}\text { Original } \\
\text { Sample (0) }\end{array}$ & $\begin{array}{l}\text { Sample } \\
\text { Mean (M) }\end{array}$ & $\begin{array}{l}\text { Standard } \\
\text { Deviation } \\
\text { STDEV) }\end{array}$ & $\begin{array}{l}\text { Standard } \\
\text { Error } \\
\text { (STERR) }\end{array}$ & $\begin{array}{l}\text { T Statistics } \\
(\mid \text { O/STERR|) }\end{array}$ \\
\hline $\begin{array}{l}\text { BO -> } \\
\text { dukungan }\end{array}$ & 0,798566 & 0,795857 & 0,045551 & 0,045551 & 17,531295 \\
\hline BO -> nilai & 0,775457 & 0,781651 & 0,057999 & 0,057999 & 13,370211 \\
\hline
\end{tabular}

Lanjutan Path Coefficients (Mean, STDEV, T-Values) Budaya Organisasi

\begin{tabular}{|l|l|l|l|l|l|}
\hline & $\begin{array}{l}\text { Original } \\
\text { Sample } \\
(\mathrm{O})\end{array}$ & $\begin{array}{l}\text { Sample } \\
\text { Mean } \\
(\mathrm{M})\end{array}$ & $\begin{array}{l}\text { Standard } \\
\text { Deviation } \\
\text { (STDEV) }\end{array}$ & $\begin{array}{l}\text { Standard } \\
\text { Error } \\
\text { (STERR) }\end{array}$ & $\begin{array}{l}\text { T Statistics } \\
\text { (|O/STERR) })\end{array}$ \\
\hline $\begin{array}{l}\text { BO -> } \\
\text { orientasi } \\
\text { pekerjaan }\end{array}$ & 0,611495 & 0,617628 & 0,097243 & 0,097243 & 6,288346 \\
\hline $\begin{array}{l}\text { BO -> } \\
\text { orientasi tim }\end{array}$ & 0,871378 & 0,871167 & 0,027776 & 0,027776 & 31,371908 \\
\hline BO -> sistem & 0,436421 & 0,432899 & 0,138899 & 0,138899 & 3,141990 \\
\hline
\end{tabular}




\begin{tabular}{|l|l|l|l|l|l|}
\hline $\begin{array}{l}\text { BO -> } \\
\text { toleransi }\end{array}$ & 0,539961 & 0,542814 & 0,096280 & 0,096280 & 5,608223 \\
\hline
\end{tabular}

Path coefisients dari tabel tersebut menunjukkan pengaruh antar budaya organisasi terhadap dimensi nya berpengaruh positif diatas 0,50 dan signifikan dengan nilai t lebih besar dari 1,96 kecuali budaya organisasi terhadap sistem imbalan karena bernilai hanya 0,4 . Stres kerja di Islamic Center Bin Baz (ICBB)

Variabel stress kerja secara operasional diukur dengan mengunakan 3 (tiga) indikator yang diadopsi dari pendapat Robbins tentang gejala stress kerja yaitu : (1) Gejala Fisiologis,(2) Gejala Psikologis, dan Gejala Perilaku

Dari tiga dimensi tersebut akan diukur indikatornya dengan 10 indikator.

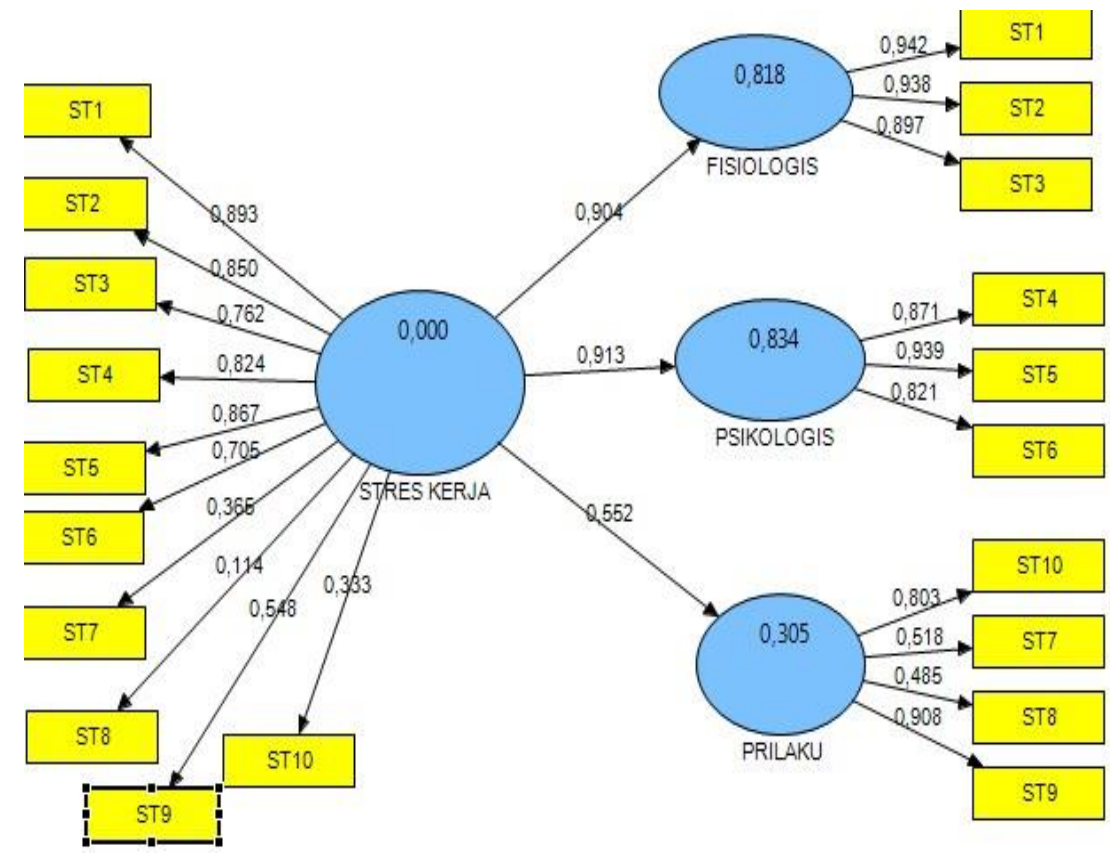

Uji Algoritma Stres Kerja

\begin{tabular}{|l|l|l|l|l|}
\hline & AVE & $\begin{array}{l}\text { Composite } \\
\text { Reliability }\end{array}$ & $\begin{array}{l}\text { R } \\
\text { Square }\end{array}$ & $\begin{array}{l}\text { Cronbachs } \\
\text { Alpha }\end{array}$ \\
\hline FISIOLOGIS & 0,857452 & 0,947470 & 0,817990 & 0,916839 \\
\hline PRILAKU & 0,493038 & 0,784066 & 0,304822 & 0,651973 \\
\hline PSIKOLOGIS & 0,771515 & 0,909902 & 0,834192 & 0,850706 \\
\hline $\begin{array}{l}\text { STRES } \\
\text { KERJA }\end{array}$ & 0,458515 & 0,878628 & & 0,841692 \\
\hline
\end{tabular}


Dari tabel 4.12 menunjukkan masing-masing nilai validitas konstuk diatas $<0,5$ kecuali perilaku sebesar 0,4 dan composite reliability dan cronbachs alpha yang baik.

Path Coefficients (Mean, STDEV, T-Values) Stres Kerja

\begin{tabular}{|l|l|l|l|l|l|}
\hline & $\begin{array}{l}\text { Original } \\
\text { Sample } \\
(0)\end{array}$ & $\begin{array}{l}\text { Sample } \\
\text { Mean } \\
\text { (M) }\end{array}$ & $\begin{array}{l}\text { Standard } \\
\text { Deviation } \\
\text { (STDEV })\end{array}$ & $\begin{array}{l}\text { Standard } \\
\text { Error } \\
\text { (STERR) }\end{array}$ & $\begin{array}{l}\text { T Statistics } \\
\text { (|O/STERR|) }\end{array}$ \\
\hline $\begin{array}{l}\text { STRES } \\
\text { KERJA -> } \\
\text { FISIOLOGIS }\end{array}$ & 0,904428 & 0,906107 & 0,020221 & 0,020221 & 44,726444 \\
\hline $\begin{array}{l}\text { STRES } \\
\text { KERJA -> } \\
\text { PRILAKU }\end{array}$ & 0,552107 & 0,574080 & 0,084815 & 0,084815 & 6,509522 \\
\hline $\begin{array}{l}\text { STRES } \\
\text { KERJA -> } \\
\text { PSIKOLOGIS }\end{array}$ & 0,913341 & 0,915140 & 0,019124 & 0,019124 & 47,7 \\
\hline
\end{tabular}

Path coefisients dari tabel tersebut menunjukkan pengaruh positif stres kerja terhadap indikatornya diatas 0,50 dan nilai $t>1,96$ yang artinya berpengaruh signifikan.

d. Pengujian Model Struktural ( Inner Model)

Inner model atau model structural mengambarkan hubungan antar variable laten berdasarkan substantive theory. Model sturuktural dengan PLS dapat menilai R-Square untuk setiap variable laten endogen sebagai kekuatan prediksi dari model Struktural (Imam Ghozali :78).

Model pengukuran yang akan digunakan pada uji analisis tersebut mengunakan teknik analisis jalur dikarenakan adanya variable intervening atau moderating sehingga memungkinkan kita menguji hubungan langsung antar variable maupun tidak langsung antar variable dalam model.

Uji hipotesis ini mengunakan sample 100 guru Islamic Center Bin Baz yang terdiri dari jenjang SU, SW, dan Aliyah. Data akan diolah dengan mengunakann sofware Smart PLS 2.0 


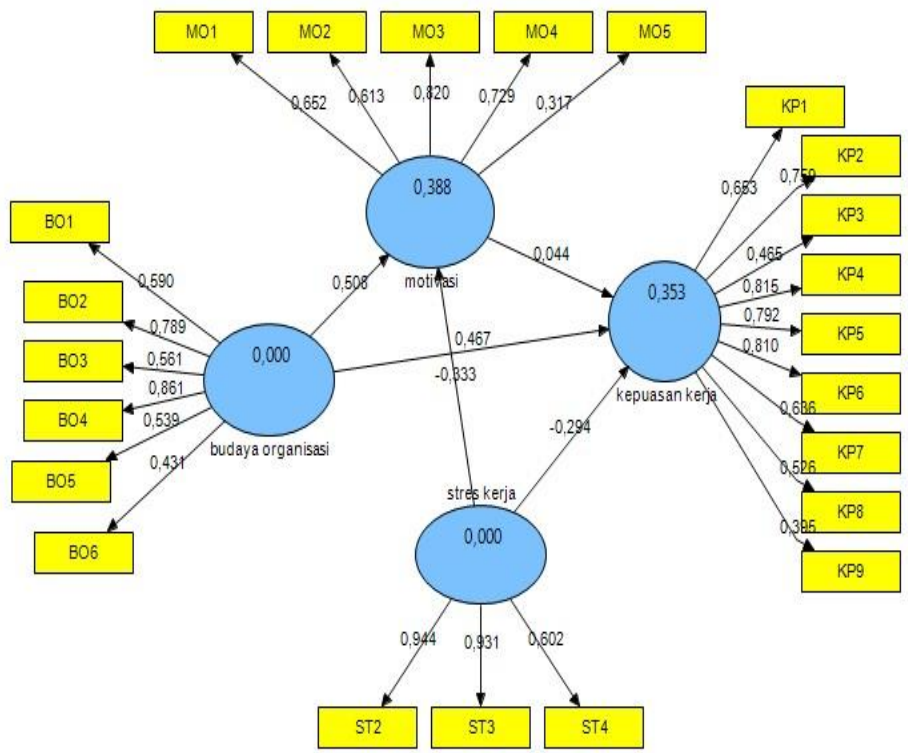

Path Coefficients (Mean, STDEV, T-Values)

\begin{tabular}{|c|c|c|c|c|c|}
\hline & $\begin{array}{c}\text { Original } \\
\text { Sample } \\
\text { (0) }\end{array}$ & $\begin{array}{c}\text { Sample } \\
\text { Mean } \\
\text { (M) }\end{array}$ & $\begin{array}{l}\text { Standard } \\
\text { Deviation } \\
\text { (STDEV) }\end{array}$ & $\begin{array}{c}\text { Standard } \\
\text { Error } \\
\text { (STERR) }\end{array}$ & $\begin{array}{l}\text { T Statistics } \\
\text { (|O/STERR } \mid)\end{array}$ \\
\hline $\begin{array}{c}\text { budaya } \\
\text { organisasi - } \\
>\text { kepuasan } \\
\text { kerja }\end{array}$ & 0,459277 & 0,484778 & 0,141620 & 0,141620 & 3,243014 \\
\hline $\begin{array}{c}\text { budaya } \\
\text { organisasi > } \\
\text { motivasi }\end{array}$ & 0,497938 & 0,496366 & 0,088924 & 0,088924 & 5,599619 \\
\hline $\begin{array}{c}\text { motivasi -> } \\
\text { kepuasan } \\
\text { kerja }\end{array}$ & 0,068680 & 0,076258 & 0,176925 & 0,176925 & 0,388188 \\
\hline $\begin{array}{c}\text { stres kerja - } \\
>\text { kepuasan } \\
\text { kerja }\end{array}$ & $-0,227628$ & $\begin{array}{c}- \\
0,267538\end{array}$ & 0,149490 & 0,149490 & 1,972693 \\
\hline $\begin{array}{l}\text { stres kerja - } \\
>\text { motivasi }\end{array}$ & $-0,373405$ & $\begin{array}{c}- \\
0,288244\end{array}$ & 0,254032 & 0,254032 & 1,989915 \\
\hline
\end{tabular}




\section{Simpulan}

Dari ouput hasil sofware PLS 2.0 , penelitian akan menginterpresikan bahwa: Pengujian hipotesis 1 : Terdapat pengaruh Budaya Organisasi terhadap Motivasi. Dari hasil hipotesis pertama menunjukkan pengaruh path coefficients sebesar 0,5 , sedangkan nilai signifikan pada pengujian sebesar 5,5> 1,96 yang artinya bahwa Budaya organisasi berpengaruh dan signifikan terhadap Motivasi. Hipotesis 1 diterima.

Pengujian Hipotesis 2 : Terdapat pengaruh Stres kerja terhadap Motivasi. Dari hasil hipotesis kedua menunjukkan pengaruh path coefficients sebesar $-0,3$, sedangkan nilai signifikan sebesar 1,97> 1,96 yang artinya Stres kerja berpengaruh dan signifikan terhadap Motivasi.Hipotesis kedua diterima.

Hipotesis ketiga : terdapat pengaruh Budaya Organisasi terhadap Kepuasan Kerja. Dari hasil hipotesis ketiga menunjukkan bahwa Budaya Organisasi berpengaruh terhadap kepuasan kerja sebesar 0,5 dan signifikan sebesar 3,2 > 1,96 yang artinya Budaya Organisasi berpengaruh dan signifikan terhadap Kepuasan kerja. Hipotesis ketiga diterima.

Hipotesis keempat : terdapat pengaruh Stres Kerja terhadap Kepuasan Kerja. Dari hasil hipotesis keempat menunjukkan pengaruh path coefficients sebesar -0,2, sedangkan nilai signifikan pada pengujian sebesar 1,97 > 1,96 yang artinya bahwa Stres kerja berpengaruh dan signifikan terhadap Kepuasan Kerja. Hipotesis 4 diterima

Hipotesis kelima : terdapat pengaruh Motivasi terhadap Kepuasan Kerja. Dari hasil hipotesis keempat menunjukkan pengaruh path coefficients sebesar 0,06, sedangkan nilai signifikan pada pengujian sebesar 0,3 <1,96 yang artinya bahwa Motivasi tidak berpengaruh dan tidak signifikan terhadap Kepuasan Kerja. Hipotesis 5 ditolak.

\section{Daftar Pustaka}

Ashar Sunyoto Munandar, Psikologi Industry dan Organisasi, Jakarta: Penerbit Universitan Indonesis (Uii-Press), 2001

Fatah Syukur, Manajemen Sumber Daya Manusia Pendidikan,Pustaka Rizki Putro, 2012

Gibson , Organisasi dan Manjemen, Cet Keempat, Gelora Aksara, 1988

Hamzah B. Uno, Teori Motivasi Dan Pengukurannya Analisis di Bidang Pendidikan, Cet 10, Jakarta, Bumi Aksara, 2013.

Hamzah B. Uno, Nina lamatenggo, Motivasi Teori dan Pengukuran, Bumi Aksara, 2012.

Husain Usman, Manajemen Teori Praktik \& Riset Pendidikan, Bumi aksara, 2008.

I Gede Putro Wibowo ( Tesis ) Pengaruh Stress Kerja Terhadap Kepuasan Kerja Dan Komitmen Organisasional Karyawan Ud. Ualam Sari Denpasar, 2014

Imam Ghozali, Partial Least Squares, Konsep Teknik Dan Aplikasi Mengunakan Program Smartpls 3.0, Universitas Diponegoro Semarang, 2012

Istijanto, Riset Sumber Daya Manusia, Cet Ketiga, Gramedia, 2005

Roidah Lina et.al (Pengaruh budaya organisasi...) 
John M. Dkk, Perilaku \&Manajemen Organisasi Gelora Aksara Pratama, Erlangga 2006.

Mahfud Sholihin, Dwi Ratmono, Analisis SEM-PIS Dengan Warppls 3., Penerbit Andi, 2013.

Malayu Dan Hasibuan, Manajemen Sumber Daya Manusia, Cet 7, Bumi Aksara, 2004.

Mila Badriah, Manajemen Sumber Daya Manusia, Pustaka Setia, 2015.

Mutiara S. Panggabean, Manajemen Sumber Daya Manusia, Cet Kedua, Ghalia Indonesia, 2004.

Nur Octaviana (Skripsi), Pengaruh Budaya Organisasi Terhadap Motivasi Dan Kepuasan Kerja Serta Kinerja Karyawan (Pada Pt. Mirota Kampus di Yogyakarta), 2011.

Robbin Stphen P., Timothy A. Judge, Perilaku Organisasi, Salemba Empat 2015.

S. Nasution, Metode Research Penelitian Ilmiah, Bumi Aksara, 2012

Siswanto Agus Sucipto, Teori \& Perilaku Organisasi Suatu Tujuan Interaktif, Cetakan 1, UIN Malang Pres , 2008.

Sondang P. Siagian, Kiat Meningkatkan Produktivitas Kerja, cet 2, rineka cipta, 2009

Sondang P.Siagian, Manajemen Sumber Daya Manusia, Cetakan 20, Jakarta: Bumi Aksara, 2012.

Sugiyono, Stastistika Untuk Penelitian, Anggota Ikatan Penerbit Indonesis ( IKAPI), 2010.

Suhas Cahyono (Tesis) Pengaruh Disiplin Kerja, Motivasi, Budaya Organisasi Dan Stress Kerja terhadap Kepuasan Kerja Guru Pada SLTA Di Bawah Yayasan Muhamadiyah Se- Kabupaten Purworejo, 2009.

Supardi,Syaiful Anwar, Dasar-Dasar Perilaku Organisasi,Cetakan Kedua, Uii Pres Jogjakarta, 2014.

T..Hani Handoko, Manajemen Personalia \& Sumber Daya Manusia, Cet 16 BPFE Yogyakarta, 2008.

Veithzal Rivai, Manajemen Sumber Daya Manusia : Dari Teori Ke Praktek, PT. Raja Grafindo Persada Jakarta, 2005.

Wexley, K,N Dan Yulk G.A, Perilaku Organisasi dan Psikolog Personalia, 2003.

Wexley, K.N Dan Yulk G.A, Organizational Behavior And Personel Psycholog, Penerjemah Shobarudddin , Jakarta: Rineka Cipta,1992.

Wuradji, The Educational Leadership Kepemimpinan Tranformasional, Cet 1, Gama Media, 2009.

Zakiyah Dradjat Dkk, Metodik Khusus Pengajaran Agama Islam , Cet 3, Bumi Aksara , Jakarta, 2004. 